\title{
AVALIAÇÃO DA FRAÇÃO RECICLÁVEL PRESENTE NOS RESÍDUOS SÓLIDOS URBANOS DOMICILIARES GERADOS EM CONDOMÍNIO RESIDENCIAL NA CIDADE DE CURITIBA-PR
}

\author{
Joel Dias da Silva \\ SENAI/SC - <joeldias@sc.senai.br>

\section{Consuelo Reis Valdiero Rodrigues} \\ consueloreis@terra.com.br
}

\begin{abstract}
RESUMO: Apresenta-se uma pesquisa quanto à adesão dos moradores de um condomínio residencial no Bairro Juvêve, na cidade de Curitiba- PR, em Setembro de 2008, ao Programa de Coleta Seletiva conduzido pela Prefeitura Municipal da cidade. A metodologia adotada foi dividida em três etapas. A primeira consistiu de pesquisa bibliográfica com objetivo de construir um referencial teórico que sustentasse a idéia da viabilidade econômica e ambiental sobre a geração de renda alternativa a partir da venda da fração reciclável presente nos resíduos sólidos urbanos domiciliares gerados em condomínios. Na segunda etapa, realizou-se uma pesquisa amostral da população residente nos edifícios com suporte de experiências relatadas na área de coleta seletiva em condomínios e do levantamento da realidade do programa na atualidade. Já a terceira etapa, compreendeu a caracterização dos resíduos sólidos urbanos, o seu acondicionamento, a segregação e a pesagem. Os resíduos foram coletados em cada um dos edifícios, separados e pesados; em seguida, selecionados os recicláveis com potencial de venda. Os dados coletados foram utilizados num processo de sensibilização dos moradores para uma adesão qualificada ao programa e serviram para estudo comparativo com os dados da Secretaria Municipal de Meio Ambiente de Curitiba. Os resultados apontam para desafios e oportunidades, associados basicamente à educação ambiental comunitária, à conquista da parceria da sociedade na solução dos problemas ligados ao gerenciamento dos resíduos e à divulgação de informações técnicas e do potencial de negócios e benefícios gerados pela cadeia produtiva da reciclagem.
\end{abstract}

Palavras-chave: Resíduos sólidos urbanos. Tratamento. Coleta Seletiva. Reciclagem. 


\section{INTRODUÇÃO}

Em 1989, a Cidade de Curitiba implantou os programas de coleta seletiva doméstica "Lixo que não é Lixo" e "Compra do Lixo", conscientizando a população para o fato da existência de materiais reaproveitáveis presentes na massa de resíduos e, que a separação do resíduo orgânico do reciclável em suas residências geraria vantagens econômicas e principalmente ambientais. Assim, os programas, além de ampliarem a vida útil do aterro sanitário, trariam a economia de energia, matérias-primas, geraria e gerar empregos, representando um esforço visando à melhoria da qualidade de vida e um combate à degradação da natureza.

Em Agosto de 2010, o Congresso Nacional publicou a Lei N. ${ }^{\circ} 12.305$ que instituiu a Política Nacional de Resíduos Sólidos, passando a ser um marco regulatório na área de resíduos no Brasil, onde o Poder Público passa a ter mais importância na previsão dos impactos sócio-econômicos e ambientais, buscando um desenvolvimento dito sustentável. Entre seus objetivos, a Lei prevê a não-geração, redução, reutilização bem como o tratamento dos resíduos, assim como a intensificação de ações de Educação Ambiental no País e aumento da reciclagem.

Segundo Zanta e Ferreira (2003) as diretrizes das estratégias de gestão e gerenciamento de resíduos sólidos urbanos buscam atender aos objetivos do conceito de prevenção da poluição, evitando-se ou reduzindo-se a geração de resíduos e poluentes prejudiciais ao meio ambiente e à saúde pública. Desse modo busca-se priorizar, em ordem decrescente de aplicação, a redução na fonte, o reaproveitamento, o tratamento e a disposição final.

Considerando o aspecto social, para Obladen (1999) citado por Takeda (2002) o envolvimento da população é necessário para a gestão participativa dos problemas relacionados com o cotidiano das pessoas, como por exemplo, a geração e o descarte de resíduos.

Este estudo construiu uma metodologia para caracterização de resíduos sólidos urbanos domiciliares em um condomínio de apartamentos bem como a sensibilização de todos os atores sociais envolvidos na minimização da problemática envolvendo os resíduos sólidos, contribuindo para a correta segregação destes com a possibilidade de geração de renda alternativa para o condomínio e/ou seus funcionários. O condomínio estudado situa-se na Rua Manoel Eufrásio n.o 634, no Bairro Juvevê, localizado na área norte da Cidade de Curitiba, o que pode ser visto na Figura 1, com destaque para sua área verde nativa preservada com $5.851 \mathrm{~m}^{2}$ de área. 
Figura 1 - Mapa de localização do condomínio

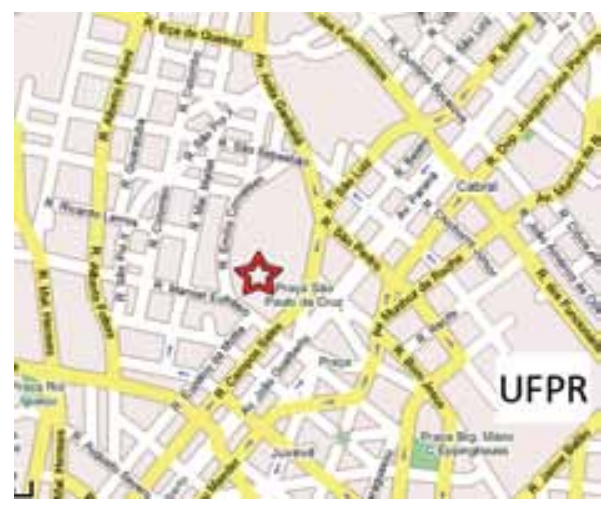

Fonte: GOOGLE MAPS 2008 - 2524'37"S e 4915'31"W a 500m de altitude

\section{OBJETIVO}

Proposição de uma metodologia para a caracterização dos resíduos sólidos urbanos domiciliares recicláveis em condomínios, visando sensibilizar os moradores frente às questões relacionadas aos resíduos sólidos e contribuir para a otimização da coleta seletiva na comunidade e na qualificação dos resíduos como fonte geradora de renda para o condomínio e/ou seus funcionários.

\section{METODOLOGIA}

Efetuou-se uma pesquisa bibliográfica às dissertações, trabalhos de conclusão de curso, livros e internet, com a finalidade de construir um referencial teórico que sustente a idéia da viabilidade econômica e ambiental da geração de renda alternativa a partir da venda da fração reciclável presente nos resíduos sólidos urbanos gerados em condomínios. Em seguida, foram realizadas entrevistas, no período da primeira quinzena do mês de Setembro de 2008, através de questionário, com o objetivo de recolher informações sobre os hábitos dos moradores em relação à coleta seletiva do município. 0 método adotado pode se caracterizar como descritivo qualitativo. A abrangência de aspectos interrelacionados e opção por incluir diversas perguntas de múltipla escolha e dicotômicas no questionário da pesquisa reforçam tal afirmação. Procurou-se explorar a temática sobre vários ângulos e permitir aos participantes, a exposição de idéias e justificativas.

\subsection{Formulação do questionário}

Constaram do questionário, além do levantamento de dados socioeconômicos, 42 quesitos, que englobaram três assuntos:

a) adesão ou não ao programa de Coleta Seletiva da prefeitura de Curitiba e aspectos afins; 
b) situação e relacionamento condominial; e

c) graus de consciência e responsabilidade social e ambiental dos pesquisados.

Na elaboração buscou-se, simultaneamente, avaliar a consistência e coerência das respostas e, ao final, dar espaço a comentários sobre a pesquisa, o que subsidiou alguns registros e conclusões. Com vistas a avaliar não só a adesão individual do programa de coleta seletiva, mas a qualidade da mesma e sua extensão no âmbito dos entrevistados, uma série de questões pertinentes foi elaborada - algumas com potencial para indicar caminhos a serem trilhados no sentido da pretendida otimização do programa. Valendose da responsabilidade sócio e ambiental dos indivíduos, questões específicas também foram incluídas na pesquisa.

\subsection{Abrangência e limitações da pesquisa}

Optou-se por um questionário de múltipla escolha, pois em se tratando ser relativamente extenso, se por um lado atendia ao propósito do estudo, por outro poderia constituir motivo para a recusa ou omissão, limitações que, de fato, foram enfrentadas. Assim, de uma metodologia idealizada com a distribuição de 112 questionários, referentes ao número total de apartamentos no condomínio, excluíram sete apartamentos vazios, e obtendo-se 35 retornos.

\subsection{Caracterização dos resíduos}

$\mathrm{Na}$ terceira etapa quantificaram-se os resíduos sólidos domiciliares gerados pelo condomínio entre os dias 16/09 à 23/09/2008. Ao se considerar a caracterização desses resíduos, por se tratar de amostragem passível de pesagem total, o procedimento foi utilizar uma balança da marca Filizola, modelo 34, com capacidade de pesagem de 0 a $150 \mathrm{~kg}$, graduada a cada 100g, para conhecer o peso total dos resíduos orgânico e/ ou inservíveis (Figura 2) e recicláveis gerados pelos apartamentos de cada edifico do condomínio, e em seguida acompanhou-se a classificação e pesagem dos resíduos recicláveis para a venda. 
Figura 2 - Pesagem dos resíduos orgânicos e/ou inservíveis

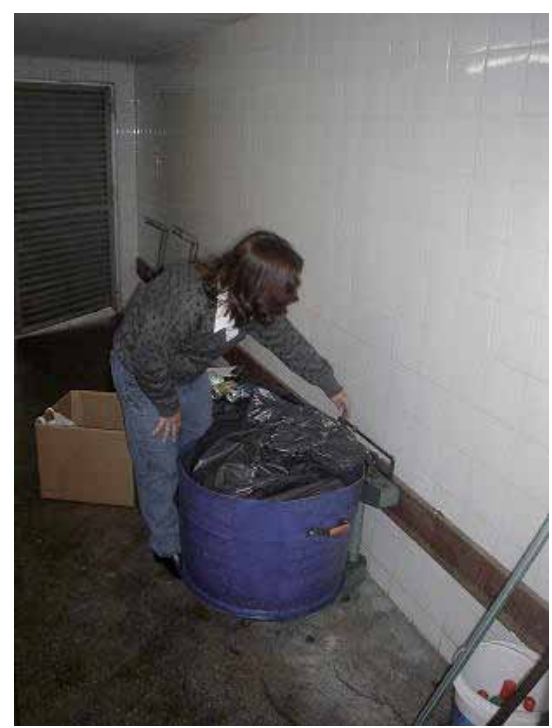

Fonte: Da autora (2008)

\section{RESULTADOS OBTIDOS}

A pesquisa exploratória revelou pontos importantes como: dados, opiniões e atitudes de uma amostra dos moradores residentes nos edifícios do condomínio, onde residem 338 pessoas. Conheceu-se o perfil sócio-econômico dos entrevistados, que representaram as famílias, suas preocupações e dúvidas com as questões ambientais. Dos 112 questionários distribuídos, apenas 35 retornaram respondidos, que passam a equivaler a amostra para nosso estudo. O perfil sócio-econômico desses entrevistados nos mostra que:

- A idade média dos entrevistados é de 50 anos;

- $54 \%$ são do sexo feminino e $37 \%$ do masculino;

- Que a escolaridade é de $51 \%$ com cursos de Pós Graduação e 37\% com superior completo;

- A renda familiar classifica-os na classe B1, segundo a Associação Brasileira de Empresas de Propaganda- ABEP que corresponde à faixa entre $\mathrm{R} \$ 3.479,36 \mathrm{e}$ $\mathrm{R} \$$ 6.563,73 em 2008;

- A média de moradores residentes por unidade habitacional é de 3.

- Em relação as suas preocupações e dúvidas com as questões ambientais responderam:

- $100 \%$ que separam seus resíduos;

- $100 \%$ têm preocupação com o meio ambiente; 
- $91 \%$ querem mais informações sobre a coleta seletiva e

- Apenas $43 \%$ souberam responder sobre o conhecimento de empresas que respeitam o meio ambiente.

Na ocasião do estudo, de acordo com a pesquisa IBOPE/Inteligência e o Jornal Paranaense Gazeta do Povo (09/10/2008), que utilizaram a mesma metodologia, ficou evidente que existe uma real diferença entre o dizer e o fazer. Separar os resíduos para a reciclagem nas classes sociais teve como resultado:

Discurso - "É a obrigação da sociedade"

Classe AA - $100 \%$

Classes ABC - 77\%

Prática - "Na minha casa eu separo"

Classe AA - 77\%

Classes $A B C-40 \%$

A análise da segregação dos resíduos recicláveis revelou alguns pontos fortes e fragilidades dessa segregação. Contribuiu também para posterior sensibilização dos moradores, através de ações de Educação Ambiental, otimizando a coleta seletiva no condomínio e aumentando o valor agregado de venda desses resíduos recicláveis, partindo-se do pressuposto que "adesão qualificada" inclui a entrega dos resíduos limpos, secos e preferencialmente em volumes compactados para melhor aproveitamento.

As Figuras 3 e 4 descrevem a segregação dos resíduos por edifício do condomínio durante a pesquisa. A quantificação dos resíduos sólidos domiciliares pesados nos deu o valor $\mathrm{kg} /$ per capita/dia gerado pelos moradores. 
Figura 3 - Resíduos coletados no Edifício Caaetê

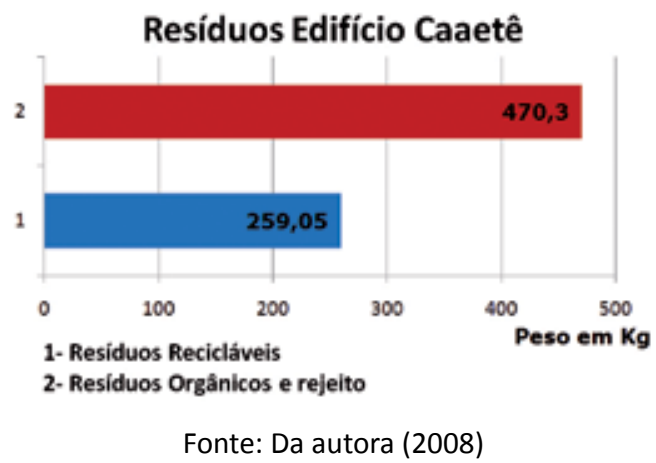

Figura 4 - Resíduos coletados no edifício Myatã

Resíduos do Edifício Myatã

2

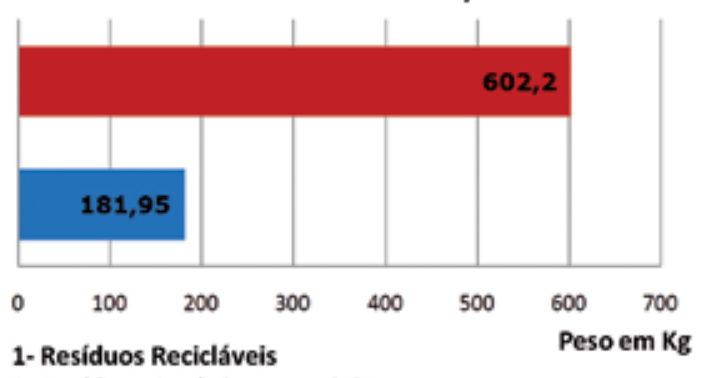

2- Residuos Orgânicos e rejeito

Fonte: Da autora (2008)

Segundo o Consórcio Municipal para a Gestão dos Resíduos Sólidos (RMC -DEZ/2007) em Curitiba tem-se 0,803 Kg per capita /dia (2006) de resíduos produzidos pela população. Embora os índices dos moradores do condomínio estejam abaixo da média curitibana, observou-se potencialidade para diminuir ainda mais com ações e estratégias de Educação Ambiental. O Edifício Caaetê com 177 moradores tem 0,6 kg per capita /dia e o Edifício Myatã, com 161 moradores, tem 0,7 kg per capita /dia.

De acordo com Takeda (2002), o percentual em peso de materiais recicláveis nos resíduos domiciliares no Brasil é em média 35\%, sendo este o teto que a taxa de desvio pode alcançar. Em Curitiba a segregação alcança 20\% (SECRETARIA MUNICIPAL DO MEIO AMBIENTE, 2008). Embora as taxas de segregação do condomínio estejam acima de valores municipais, como mostram as Figuras 5 e 6, estas podem passar por melhoria contínua. 
Figura 5 - Resíduos recicláveis separados no edifício Caaetê

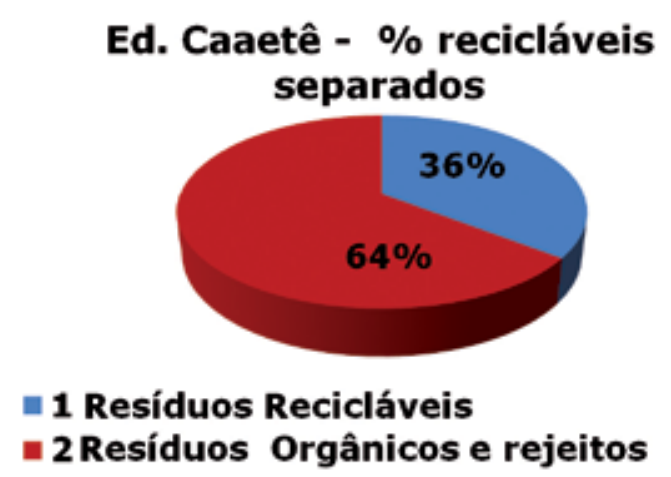

Fonte: Da autora (2008)

Figura 6-Resíduos recicláveis separados no edifício Myatã

\section{Ed. Myatã - \% recicláveis separados}

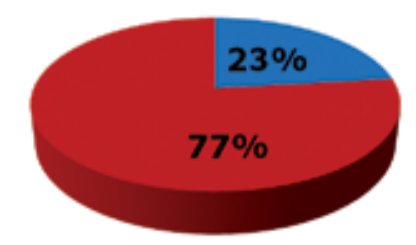

" 1 Resíduos Recicláveis

- 2 Resíduos Orgânicos e rejeitos

Fonte: Da autora (2008)

Em relação aos resíduos recicláveis verdadeiramente aproveitáveis para a venda foi observado que somente $22 \%$ da segregação dos dois edifícios, gerou renda, como mostra a Figura 7, devido a :

- Segregação inadequada na fonte geradora;

- O baixo valor de venda para o volume agrupado devido a falta de espaço para armazená-los;

- O baixo valor comercial dos resíduos recicláveis descartados. 


\section{Recicláveis Aproveitáveis}

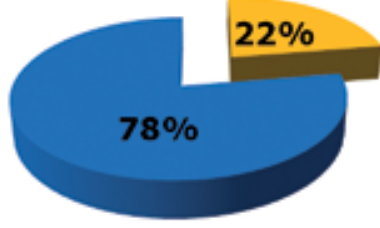

\section{= 1 Recicláveis Aproveitáveis \\ - 2 Recicláveis Rejeitados}

Fonte: Da autora (2008)

A identificação dos tipos de resíduos sólidos possibilita diversas ações na área de gestão ambiental. Uma das ações é a que permite a elaboração de um plano de ação visando à minimização dos resíduos domésticos identificados, num trabalho de sensibilização e conscientização dos moradores sobre a importância da redução, reutilização e segregação do resíduo e o papel do morador nesse processo.

Outro aspecto que pode ser trabalhado é a aplicação de ferramentas de gestão, com o estudo da viabilidade de encaminhamento dos resíduos previamente selecionados no condomínio para empresas de reciclagem que compram esses resíduos. Com o conhecimento do perfil dos resíduos gerados ficará mais fácil viabilizar uma estratégia de redução de geração de resíduos, com base em uma ação de conscientização junto aos moradores.

Ações como estas podem apresentar um aprimoramento de metas junto ao Programa de Coleta Seletiva da cidade que pode ser proposta a partir desta pesquisa, otimizando a coleta dos resíduos no condomínio, tornando-a eficaz nos quesitos referente à qualidade da segregação e os resultados.

\section{CONSIDERAÇÕES FINAIS}

Diante de novos rumos que as questões ambientais estão tomando como a obrigatoriedade da preservação dos recursos naturais, da necessidade de economizar energia e principalmente na brusca mudança ocorrida na composição do lixo nos últimos anos, como o aumento de materiais recicláveis, a problemática dos resíduos sólidos é preocupante. Para tentar reduzir essa quantidade de malefícios gerados, a coleta seletiva é apontada como uma boa solução. No entanto, a participação da comunidade é importante e Educação Ambiental é uma ferramenta fundamental neste processo. 
Segundo Abreu (2001) no mundo inteiro, a nova ordem é reduzir a geração de resíduos. No Brasil, essa questão foi mais difundida com a Agenda 21, documento elaborado por 170 países que participaram da ECO-92 no Rio de Janeiro. Nesse documento, foi estabelecido o princípio dos 3R's: Reduzir, o consumo de produtos e o desperdício de materiais; Reutilizar e Reciclar os materiais.

Nesta hierarquia, considera-se que reduzir ou evitar a geração dos resíduos nas fontes geradoras causa menos impacto do que reciclar os materiais após o seu descarte. Entretanto, implantar o primeiro $R$ é um grande desafio, porque significa interferir na sensação de liberdade e de felicidade das pessoas ou mesmo do poder pessoal que advém com o direito de consumir o quanto quiser. $O$ conceito de pessoa confunde-se com o de consumidor que, a cada momento, se vê diante de novas necessidades de consumo, num movimento crescente de desperdício de matéria-prima e de energia, além do aumento da geração e descarte de resíduos. Assim, os programas de redução destes resíduos, devem ter um caráter cultural, investindo nas mudanças de hábitos e de consumo da população. Também é importante a discussão do aspecto legal, buscando a aprovação de leis que favoreçam a minimização da produção de descartáveis pela indústria.

Para incentivar a reutilização de materiais poderão ser criadas centrais de trocas comunitárias para o reaproveitamento de objetos, estimulando artistas e artesões a reutilizarem materiais descartados. Também deve ser incentivada a reutilização de embalagens para conservas ou doces, o comércio de produtos a granel e o melhor aproveitamento dos alimentos.

Outra ação importante é incentivar e apoiar estabelecimentos que lidem com bens usados como os brechós e sebos e oficinas de reparos para recuperação, restauração ou recondicionamento de produtos, aumentando a vida útil de roupas, sapatos, aparelhos e mobiliário. $\mathrm{Na}$ implantação de um programa de coleta seletiva, na perspectiva da minimização, as atividades devem proporcionar oportunidades de geração de trabalho e renda para a população carente, prioritariamente em parceria com os catadores.

Há ainda certa mística em torno do terceiro $R$, o da reciclagem, que muitas vezes, é vista como a panacéia para os problemas do consumismo e da excessiva geração de resíduos. Quando, como vimos, a problemática ambiental precisa ser racionalmente analisada num entorno mais amplo, numa visão interdisciplinar dos agentes envolvidos neste processo e de difícil entendimento.

Entretanto a reciclagem de materiais, apesar de ser um processo menos poluente e que consome menos matérias-primas virgens, água e energia, ainda gera resíduos. Muitos programas de coleta seletiva com enfoque apenas na reciclagem não questionam os níveis de desperdício e podem até se beneficiar com eles. Alguns fabricantes de embalagens admitem que os seus projetos de reciclagem contribuam para aumentar o consumo dessas embalagens. Os programas de coleta seletiva não devem, portanto, ter como objetivo apenas coletar os materiais para reciclar com a meta" quanto mais recicláveis melhor", mas sim reduzir o consumo o desperdício para ter o resultado "quanto menos resíduos, melhor". 
Segundo Cinquetti (2004), diante da constatação de que vem aumentando muito o consumo de bens e o conseqüente descarte de resíduos, além de abordar a questão da disposição, vem sendo consensual a constatação de que é preciso minimizar o montante. Questiona-se: "Que orientação a literatura ambientalista vem propondo quanto à minimização dos resíduos?"

Embora a mídia e certos projetos educativos freqüentemente sugiram a solução para reduzir a quantidade de resíduos seja a reciclagem, a literatura mais recente (Agenda $X X I$ - Rio 92) recomenda a reciclagem como o último dos chamados $3 R^{\prime}$, precedida pela redução de consumo e do desperdício e da reutilização de produtos. Causamos por exemplo, menos impacto ambiental eliminando o consumo de descartáveis (filtro de café e guardanapos de papel, fraldas, canudos, copos plásticos descartáveis) do que se reciclando ou reutilizando tais produtos. A reciclagem de qualquer material implica em impactos, pelo gasto de energia no processo industrial e no transporte dos materiais recicláveis, pelos recursos naturais adicionados no caso dos materiais que requerem adição de matéria prima e por ser uma atividade poluente.

É importante observar, diante da insistência da mídia na reciclagem, que mesmo quando idealmente os resíduos de uma pessoa ou cidade sejam minimizados, passando pelos $3 R^{\prime}$ 's, sempre restarão resíduos, que precisão ser destinados, preferencialmente, a um aterro sanitário. Hoje 405 municípios como mostra a Figura 8, ou seja, 26 milhões de brasileiros têm acesso a programas de coleta seletiva no país (CEMPRE, 2008).

Figura 8 - Número de municípios brasileiros com programas de Coleta Seletiva.

Municípios com Coleta Seletiva no Brasil

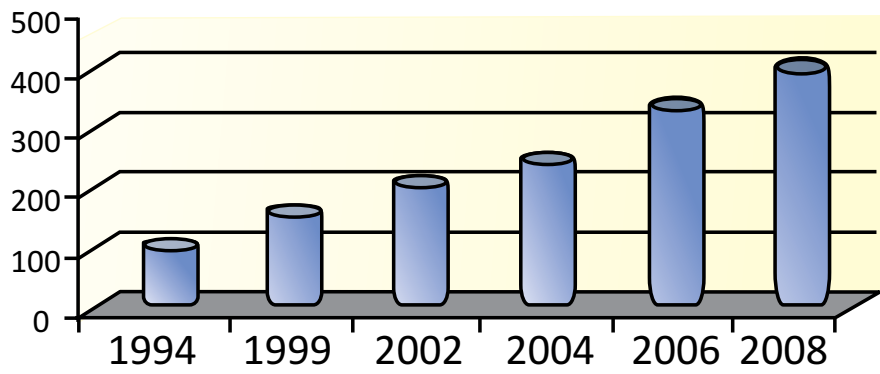

Fonte: CEMPRE, 2008

Informações de CEMPRE (2008) mostram que a concentração dos programas permanece nas regiões Sudeste e Sul do país, conforme a Figura 9. Do total de municípios brasileiros com coleta seletiva, $83 \%$ estão situados netas regiões. Distribuição dos municípios com Coleta Seletiva por regiões: Norte (07); Centro-Oeste (16); Nordeste (44); Sul (143); Sudeste (195). 
Figura 9 - Distribuição por região brasileira com programa de Coleta Seletiva.

Distribuição dos Municípios com Coleta Seletiva no Brasil

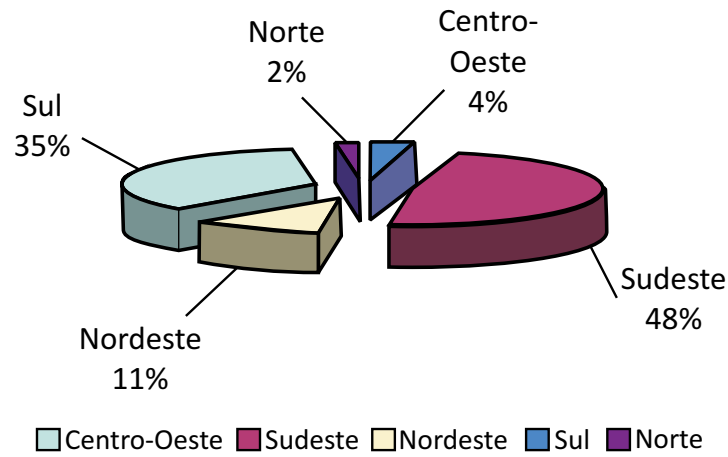

Fonte: CEMPRE, 2008

Se hoje conseguíssemos idealmente reduzir ao mínimo o desperdício e o consumo, reutilizar e reciclar todos os resíduos possíveis, ainda restaria resíduo, como papel higiênico e objetos feitos de materiais para os quais não há reciclagem (tais como couro, lâmpadas, espelho, tecido, espuma e fralda descartável). Além disso, algumas tecnologias de reciclagem (como as embalagens longa- vida e as de madeira) não são acessíveis para boa parte das cidades brasileiras. O envolvimento de pessoas com programas de coleta seletiva requer esforços individuais, coletivos e governamentais para mudar hábitos ou implantar políticas públicas com estes programas e de reciclagem. Poucos recursos literários questionam o consumismo e/ou apontam caminhos individuais ou coletivos para pensá-lo. O consumo é visto como inevitável, restando-nos investir em tecnologias para a reciclagem. É uma posição fatalista diante do consumismo, em que a reciclagem tem como função aliviar a consciência do consumidor, que terá seus resíduos reciclados. Limitações locais ou regionais (mercado, tecnologias disponíveis, existência de programas de coleta seletiva), o que pode inviabilizar ações de Educação Ambiental e Gestão Ambiental quanto ao descarte, à coleta seletiva e à reciclagem.

Outro aspecto a comentar sobre a reciclagem diz respeito ao mercado para os produtos recicláveis. A falta de compradores para os resíduos pode inviabilizar programas de coleta seletiva em escolas, condomínios e cidades. As restrições ao mercado de recicláveis dizem respeito inclusive aos resíduos já convencionalmente tidos como passíveis de reciclagem: papel, plástico, vidro e metais. Muitas vezes não há quem compre plásticos ou vidro na cidade. Às vezes as limitações são sazonais, o que talvez dificulte ainda mais o programa, pois ora o vidro tem mercado, ora não tem. Ou como no nosso caso na ocasião do estudo não havia compradores para embalagens Tetra-pak ou o decréscimo no valor do peso do material: 
- Papelão - 50\%;

- Vidro - 30\%;

- Jornal - $25 \%$;

- Latas de alumínio - $30 \%$

Segundo Conceição e Silva (2009) a reciclagem em si, não apresenta uma alternativa econômica; somente ameniza momentaneamente as pressões sociais sobre o desemprego e propicia um ganho pelas indústrias, por meio da redução dos seus custos; e estas, utilizando-se dos sucateiros, controlam o mercado de produtos de reciclados. De acordo com Valério et al. (2008), citando Demajorovic (1995), uma política de gestão de resíduos deve atuar de forma não só a garantir a coleta, o tratamento e a disposição, mas principalmente deve estimular a produção de uma menor quantidade de resíduos desde a sua geração. A política ambiental deve ter como prioridade um sistema circular no qual a quantidade de resíduos reaproveitados seja cada vez maior e a de resíduos gerados, cada vez menores.

Diante deste cenário preocupante e da necessidade de criação de novas alternativas que minimizem o problema da geração de resíduos domésticos, sugerimos a implementação de taxas diferenciadas sobre a coleta de resíduos residencial, a qual será cobrada sobre a produção excedente destes resíduos, estipulando-se uma cota máxima para cada moradia. A taxação será imposta sobre o peso de resíduos excedente. Em Seattle, no Estado de Washington - EUA, por exemplo,quando o número de containers usados no mês é reduzido, os residentes são premiados com a diminuição do preço dos serviços de coleta e disposição dos resíduos. Devemos quebrar o elo entre crescimento econômico e crescimento na produção de resíduos.

Em alguns municípios brasileiros é cobrada uma taxa de lixo, que tem como base de cálculo a mesma forma de incidência que o IPTU, ou seja, é cobrada de acordo com a região da cidade e o valor do imóvel. Desta forma, todos os contribuintes são penalizados da mesma maneira, não se diferencia quem produz muito de quem produz pouco resíduo, e não ocorre um desincentivo a produção desses resíduos. A taxa de lixo na forma que é cobrada no Brasil só serve para gerar receita para os municípios, não tendo nenhuma função "educacional preventiva". A proposta de adoção de taxação sobre a quantidade de resíduos produzida tem por objetivo estimular a redução na produção destes resíduos, assim como incentivar a população para o consumo ecologicamente correto e investir em projetos de coleta seletiva e reciclagem. Desta forma, além de reduzir a produção de resíduos sólidos urbanos domiciliares haveria um aumento na reutilização dos resíduos gerados.

É fundamental que todos os agentes econômicos tornem-se socialmente responsáveis: os produtores deveriam fazer produtos recicláveis, com embalagens que gerem menos resíduos, ou seja, ecologicamente corretas; os consumidores deveriam adquirir produtos com menos embalagens, utilizar ecobags ao fazerem suas compras evitando 
sacos plásticos; as autoridades locais deveriam incentivar programas de coleta seletiva, separação e reciclagem dos resíduos; além de promover propagandas educativas que incentivem os consumidores a ter uma visão mais consciente sobre os problemas gerados pelos resíduos e sobre as ações que podem ser feitas para minimizá-lo (consumo consciente); as indústrias deveriam introduzir a reciclagem na etapa produtiva e evitar o desperdício de matéria prima.

O Programa de Coleta Seletiva de Curitiba não visa resolver todos os problemas dos resíduos sólidos da comunidade, mas estes programas alcançaram um excelente nível devido ao trabalho do departamento de limpeza pública ao longo dos anos, que além de ter um planejamento detalhado de todos os serviços, acima de tudo tem conhecimento dos problemas relacionados com os resíduos sólidos. Esta organização e abertura de dados possibilitaram este trabalho. Como foi observado um aumento contínuo de materiais recicláveis ao longo destes anos através dos estudos dos diversos programas da cidade, é possível se fazer um prognóstico para o futuro. A manutenção destes programas é imprescindível onde eles existem, além de servir de exemplo para os demais municípios brasileiros. Nenhum projeto de gerenciamento ambiental alcançará sucesso no que diz respeito à redução dos impactos ambientais e a conseqüente conservação dos recursos naturais, se não ocorrer simultaneamente ao processo a sensibilização dos atores e atrizes envolvidos. A continuidade deste projeto contribuirá no aprimoramento da Gestão de Resíduos no condomínio, tornando-o uma referência para todos os interessados em conduzir projetos de gestão de resíduos com atuação responsável e cidadã.

\title{
ASSESSING THE RECYCLABLE PORTION WITHIN THE URBAN SOLID WASTE PRODUCED IN RESIDENTIAL CONDOMINIUMS IN THE CITY OF CURITIBA-PR
}

\begin{abstract}
A poll was held among the dwellers of a residential condominium in the Juvevê Neighborhood in Curitiba-PR in September 2008 as to survey their willingness to carry out the Waste Sorting Program that the city administration holds in Curitiba. Three stages have made up the methodology used. The first stage was a bibliographic research aiming to build up a theoretical references set on which to support the economical and environmental viability on alternative money making from selling the recyclable portion within the urban solid waste produced in residential condos. The second stage occurred through sample analyzing the buildings' residents according to their reported experience concerning waste sorting in condominiums as well as through looking into the facts of the program as it is carried today. While the third stage has comprised the urban solid waste characterization and packing, as well as its sorting out and weighing. In each building there has been collecting, sorting, and weighing of the waste; and afterwards those portions which were recyclable and therefore feasible for selling have been separated. The information gathered through the study was shown to all the other condo dwellers as a means of eliciting their qualified joining in the program and these data were also
\end{abstract}


helpful for a comparative study to the City's Environment Secretary Data. The study results point towards some challenge and opportunities which are basically associated with environmental education for the community; and with having the society involved in solving problems linked to waste management.

Keywords: Urban Solid Waste, Waste Sorting, Recycling, Residential Condominiums, Environmental Education.

\section{REFERÊNCIAS}

ABREU, Maria de Fátima. Do Lixo à Cidadania - estratégias para ação. Brasília: Caixa, 2001. $94 \mathrm{p}$.

CEMPRE, 2008. Disponível em: <http://www.cempre.org.br/ciclosoft_2008.php >. Acesso em : 18 jul.2008.

CINQUETTI, H.S. Lixo, resíduos sólidos e reciclagem: uma análise comparativa de recursos didáticos. Educar, Curitiba, n.23, p.307-333, 2004.

CONCEIÇÃO, Márcio Magera; SILVA, Orlando Roque da. A Reciclagem dos Resíduos Sólidos Urbanos e o uso das Cooperativas de Reciclagem- Uma alternativa aos problemas do Meio Ambiente - Enciclopédia Biosfera, Goiânia, vol.5, n.8, p. 1-16, 2009.

TAKEDA, A. K. . Análise da Gestão dos Resíduos Sólidos Urbanos da Cidade de Curitiba com Abordagem na Coleta Seletiva e Domiciliar. 2002. 277 f. Dissertação (Mestrado em Engenharia Ambiental)- Universidade Federal de Santa Catarina, Florianópolis, 2002.

ZANTA, V.M.; FERREIRA, C. F.A. Gerenciamento integrado de resíduos sólidos urbanos: aterro sustentável para municípios de pequeno porte - resíduos sólidos urbanos. Rio de Janeiro: ABES, projeto PROSAB, 2003. p. 1-16.

VALERIO, Diogo; SILVA, Taís Carestiato da; COHEN, Claude. Redução da Geração de Resíduos Sólidos: Uma Abordagem Econômica. 2008. Disponível em: <http;/www. anpec.org.br/encontro2008/artigos/20080711417570-pdf> Acesso em: 03 mar. 2010. 


\section{SOBRE OS AUTORES}

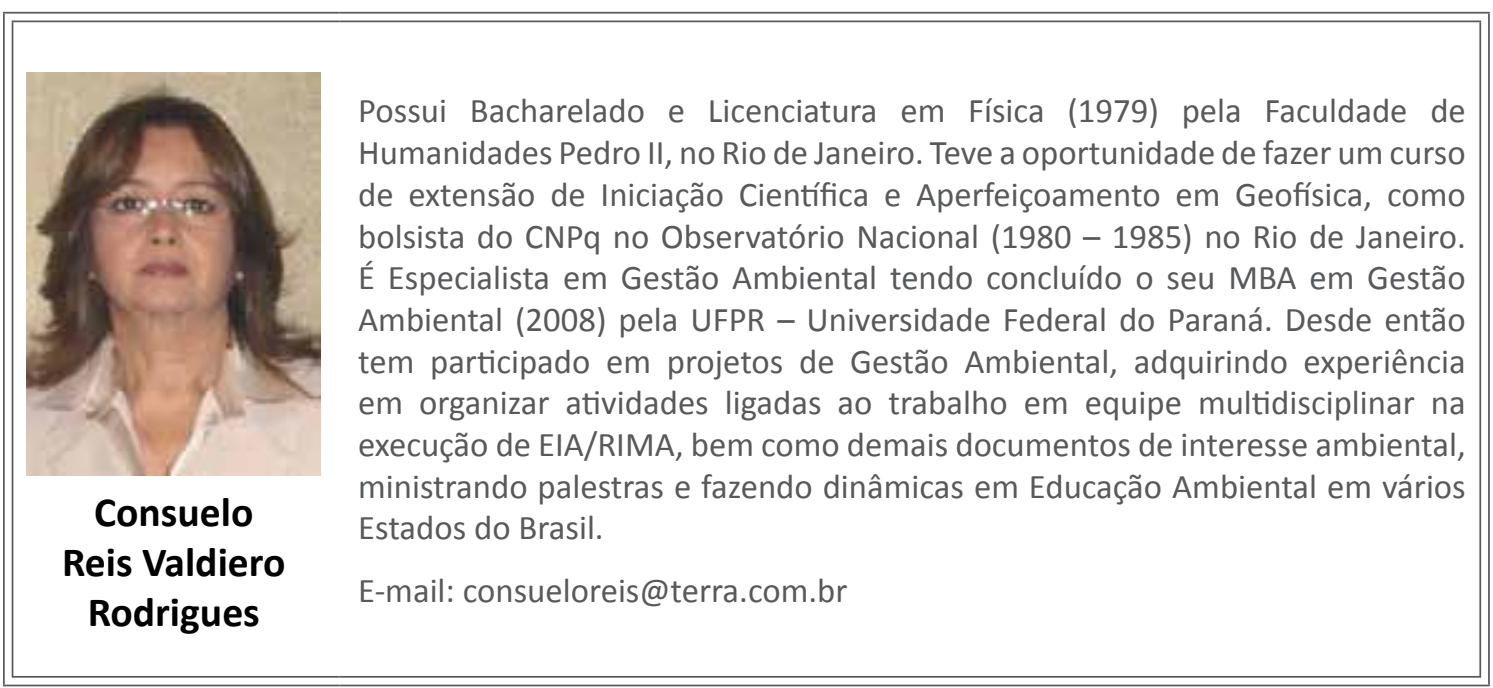

\begin{tabular}{|l} 
Engenheiro Sanitarista e Ambiental (1999) pela UFMT - Universidade Federal \\
de Mato Grosso, com Mestrado (2002) e Doutorado (2007) em Engenharia \\
Ambiental, ambos pela UFSC - Universidade Federal de Santa Catarina. \\
Atualmente é bolsista do Programa MEC/CAPES PNPD, realizando o seu Pós- \\
Doutorado em Engenharia Ambiental na FURB - Universidade Regional de \\
Blumenau junto ao Programa de Pós-Graduação em Engenharia Ambiental, e \\
Instrutor Nível III do CursoSuperior de Tecnologia em Gestão Ambiental doSENAI \\
- Serviço Nacional de Aprendizagem Industrial, também em Blumenau, Santa \\
Catarina. Professor colaboradore orientador do Mestrado Profissionalizante em \\
Engenharia Ambiental com Ênfase em Gestão Ambiental, parceria entre a UFSC \\
- Universidade Federal de Santa Catarina e do ICE - Instituto de Competências \\
Empresariais representando a FIAT Automóveis. Possui experiência na Grande \\
Área da Engenharia Sanitária e Ambiental, com ênfase em Resíduos Sólidos \\
Urbanos e Industriais, assim também como Efluentes Industriais e Tecnologias \\
de Tratamento. Tem atuado principalmente na pesquisa e orientação dos \\
seguintes temas: Resíduos Sólidos Urbanos, Gerenciamento de Resíduos, \\
Aterros Sanitários, Tratamento de Efluentes Têxteis e Subprodutos, e também \\
Aspectos e Impactos Ambientais. \\
E-mail: dias joel@hotmail.com
\end{tabular}

